\title{
The Research Hot Topics of The Physics Teacher in the Recent Five Years
}

\author{
Xizhen Wu, Xinwei Fan, Peng Chen, Zhaoyang Peng* \\ College of Physics and Electronics, Yunnan Normal University, Kunming, China \\ Email: *pengzhaoyang412@163.com
}

How to cite this paper: Wu, X.Z., Fan, X.W., Chen, P. and Peng, Z.Y. (2021) The Research Hot Topics of The Physics Teacher in the Recent Five Years. Open Access Library Journal, 8: e8057.

https://doi.org/10.4236/oalib.1108057

Received: October 8, 2021

Accepted: November 5, 2021

Published: November 8, 2021

Copyright $\odot 2021$ by author(s) and Open Access Library Inc.

This work is licensed under the Creative Commons Attribution International License (CC BY 4.0).

http://creativecommons.org/licenses/by/4.0/ (c) (i) Open Access

\begin{abstract}
This research uses BICOMB, UCINET and other bibliometric analysis software to extract keywords, statistically and visually analyze the 1463 articles of The Physics Teacher in the past five years, and obtains its research hotspots and directions in the past five years and obtains some enlightenment from it. Among them, the main research hotspots of physics teaching are teaching, physics teaching aids, educational evaluation, Newtonian mechanics, physics experiment, education policy and management, learning mode, electromagnetics, student development, physics history, kinematics, geometric optics, etc.
\end{abstract}

\section{Subject Areas}

Educational Reform

\section{Keywords}

The Physics Teacher, Physics Teaching, Research Hotspots

\section{Introduction}

Timely understanding of the context and dynamics of research on physics teaching in middle schools in China can provide new perspectives for such academic research [1]. Focusing on international physics teaching hotspots can absorb outstanding foreign research results, enhance international perspectives, and promote teaching reform and innovation. The article " 40 Years of Middle School Physics Teaching Research: Core Themes and Evolution Trends-Based on the Visual Analysis of 12173 Papers in The Physics Teacher (in Chinese) from 1980 to 2020" in the core journal The physics teacher (in Chinese) in the 
field of physics education in China shows that since the establishment of The Physics Teacher (in Chinese), the research hotspots and core topics are mainly distributed in the fields of physics knowledge teaching, force and motion, electricity, physics experiment, electromagnetic induction, geometric optics, physics core literacy training and practice [1]. What are the research hotspots of The Physics Teacher as an international publication? Mastering the research hotspots of such publications can help us find a better direction in academic research. However, there are still few documents on this aspect in China. Therefore, this article uses bibliometric analysis software to analyze the results of The Physics Teacher in the past five years. Explore hot topics and get some inspiration from them, hoping to provide some help to physics educators.

\section{Data and Methods}

\subsection{Data Source}

The international publication The Physics Teacher, issued by the American Association of Physics Teacher (AAPT), was published in April 1963 and has been loved by many physicists. The authors set up an advanced search on CNKI as The Physics Teacher and published time from 2016.01.01-2021.3.13. The result was 1463 articles. Then export the searched literature results and manually delete invalid literature, and import the valid data into the BICOMB software [2] for keyword extraction, statistics and matrix generation.

\subsection{Research Tools and Research Process}

Knowledge graph is an important method that has emerged in the field of library and information science in recent years. It combines the theories and methods of applied mathematics, graphics, information visualization technology, information science and other disciplines with metrological citation analysis, co-occurrence analysis and other methods. Use the visual atlas to visually display the core structure, development history, frontier fields and overall knowledge structure of the research field [3]. This research uses BICOMB, UCINET and other software as the main research tools. First, the documents are exported from CNKI and imported into BICOMB software for basic statistical analysis, manual deletion of invalid documents, statistical ranking of keywords appearing in the documents, and high-frequency words with a word frequency greater than 20 as the main keywords. Secondly, import the generated co-occurrence matrix into UCINET software to obtain a high-frequency keyword network map, and generate a clustering theme map, so that the hot themes and directions of The Physics Teacher in the past five years can be seen intuitively and clearly.

\section{Research Results}

\subsection{High-Frequency Keywords Obtained}

After retrieval and statistics, a total of 2262 keywords were obtained. The keyword threshold is set to 20 , and 72 high-frequency words with a word frequency 
greater than 20 are counted, and the cumulative percentage is $56.16 \%$. The statistical results of high-frequency words are shown in Table 1.

Table 1. Results of high-frequency words.

\begin{tabular}{|c|c|c|}
\hline Serial number & Key field & Frequency of occurrence \\
\hline 1 & Teaching & 581 \\
\hline 2 & Educational aids & 385 \\
\hline 3 & Education & 367 \\
\hline 4 & Educational assessment & 310 \\
\hline 5 & Educator & 161 \\
\hline 6 & Physicists & 139 \\
\hline 7 & Newtonian mechanics & 127 \\
\hline 8 & News and events & 113 \\
\hline 9 & Careers and professions & 106 \\
\hline 10 & Books & 97 \\
\hline 11 & Lectures & 96 \\
\hline 12 & Scholarly publishing & 95 \\
\hline 13 & Measuring instruments & 90 \\
\hline 14 & Chemical elements & 86 \\
\hline 15 & Laboratories & 82 \\
\hline 16 & Public policy and governance & 73 \\
\hline 17 & Universities & 72 \\
\hline 18 & Journal & 69 \\
\hline 19 & Polymers & 63 \\
\hline 20 & Batteries & 58 \\
\hline 21 & Rotational dynamics & 57 \\
\hline 22 & Funding & 51 \\
\hline 23 & Energy conservation & 50 \\
\hline 24 & Musical instruments & 47 \\
\hline 25 & Learning and learning models & 47 \\
\hline 26 & Friction & 46 \\
\hline 27 & Electromagnetism & 44 \\
\hline 28 & Students & 44 \\
\hline 29 & History of science & 42 \\
\hline 30 & Abstracts & 41 \\
\hline 31 & Free-body diagrams & 40 \\
\hline 32 & Visual system & 39 \\
\hline 33 & Transition metals & 38 \\
\hline 34 & Gravitational force & 37 \\
\hline
\end{tabular}




\section{Continued}

\begin{tabular}{|c|c|c|}
\hline 35 & Outreach & 37 \\
\hline 36 & Electrostatics & 36 \\
\hline 37 & Lenses & 34 \\
\hline 38 & Optical imaging & 34 \\
\hline 39 & Scientific society and organization & 34 \\
\hline 40 & Kinematics & 32 \\
\hline 41 & General physics & 30 \\
\hline 42 & Microphones & 29 \\
\hline 43 & Interviews & 29 \\
\hline 44 & Electrical circuits & 27 \\
\hline 45 & Conference & 26 \\
\hline 46 & General relativity & 25 \\
\hline 47 & Special relativity & 25 \\
\hline 48 & Leptons & 25 \\
\hline 49 & Astronomers & 24 \\
\hline 50 & Thermal instruments & 24 \\
\hline 51 & Awards and Prizes & 24 \\
\hline 52 & Text books & 24 \\
\hline 53 & Magnetic equipment & 24 \\
\hline 54 & Programming languages & 24 \\
\hline 55 & Sensors & 24 \\
\hline 56 & Corrections & 24 \\
\hline 57 & Fundamental constants & 23 \\
\hline 58 & Internet & 23 \\
\hline 59 & Electrodynamics & 23 \\
\hline 60 & Telecommunications engineering & 23 \\
\hline 61 & Diversity in science & 22 \\
\hline 62 & Buoyancy & 22 \\
\hline 63 & Magnetic fields & 22 \\
\hline 64 & Geometrical optics & 22 \\
\hline 65 & Data acquisition & 22 \\
\hline 66 & Regression analysis & 21 \\
\hline 67 & National Aeronautics and Space Administration & 21 \\
\hline 68 & Thermodynamic states and processes & 21 \\
\hline 69 & Geodesy & 20 \\
\hline 70 & Classical mechanics & 20 \\
\hline 71 & Speed of sound & 20 \\
\hline 72 & Oscilloscopes & 20 \\
\hline
\end{tabular}




\subsection{Building a Social Network and Clustering Map of High-Frequency Words}

In the high-frequency word social network graph, the position of each node represents a different keyword, the connection between the keywords represents its internal connection, the size of the node represents centrality, and the larger the node, the more central [4]. The authors imported the high-frequency word co-occurrence matrix obtained by BICOMB software into the UCINET software, and generated the high-frequency word social network graph according to the parameters such as the centrality of the keywords, the position and the mutual relationship in the network graph, and then performed k-aggregation. The clustering map is obtained by class analysis, as shown in Figure 1. The larger the label in the figure, the stronger the keyword centrality and the higher the frequency of co-occurrence. Different label colors represent different clusters.

The high-frequency word network diagram shown in Figure 1 shows the research hotspots of different clusters. The larger the label of the same color, the more relevant research on the topic. It can be seen from Figure 1 that the research clusters of The Physics Teacher in the past five years are mainly distributed in physics teaching, physics education technology, general physics, and physics discussion. Among them, the research hotspots related to middle school physics teaching in these clusters mainly include: teaching, physics teaching aids, educational evaluation, Newtonian mechanics, physics experiments, educational

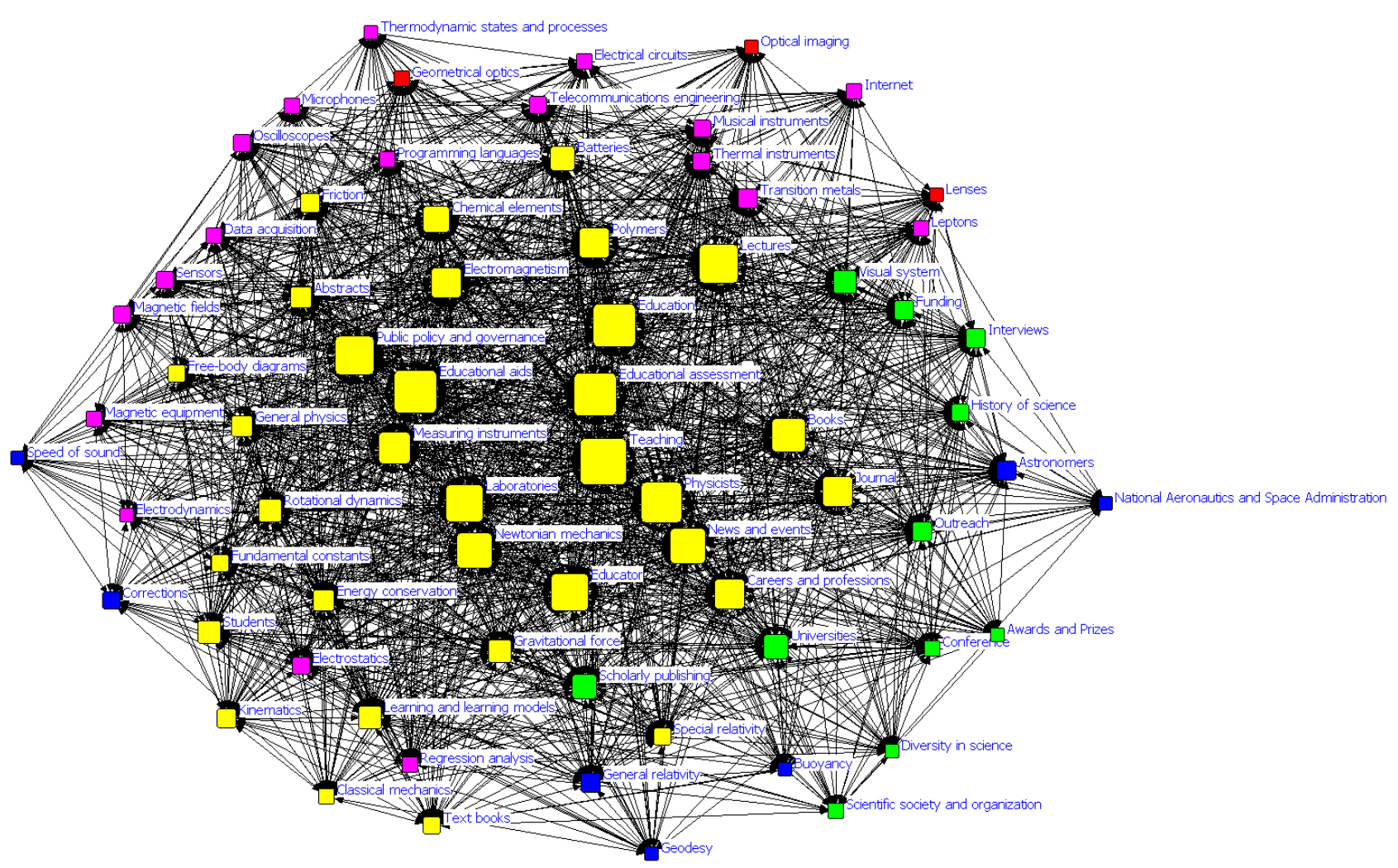

Figure 1. High-frequency word social network and clustering map. 
policies and management, learning modes, electromagnetics, student development, physics history, sports Science, geometric optics, etc. The marginal areas of the map, such as the Internet, textbook analysis, and other relatively low-frequency words, reflect the trend of future research to a certain extent, and may become new hotspots and cutting-edge trends in physics teaching research.

\section{Discussion of Results}

\subsection{Summary}

The research hotspots of The Physics Teacher in middle school physics teaching mainly include teaching [5], physics teaching aids [6], educational evaluation [7], Newtonian mechanics [8], physics experiments [9], education policy and management [10], Learning Mode [11], Electromagnetism [12], Student Development [13], History of Physics [14], Kinematics [15], Geometric Optics [16], etc.

\subsection{Comparison with the Core Themes of Middle School Physics Teaching Research of The Physics Teacher (in Chinese)}

The research found that the sample literature of middle school physics teaching research presents the characteristics of wide research fields and prominent research topics. The research hotspots and core themes are mainly distributed in physics knowledge teaching, force and motion, electricity, physics experiments, electromagnetic induction, geometric optics and physics Discipline core literacy cultivation practice and other fields [1].

Compared with The Physics Teacher (in Chinese), The Physics Teacher pays more attention to research in the fields of student development, physics history and physics teaching aids, which reflects the difference between Chinese and international physics education to a certain extent. The 2005-2014 research shows that there is a big difference between Chinese and international physics education hot issues.

First of all, physics education in China has uneven performance in various hotspots of international physics education. Second, physics education and the development of physics cognition are not highly integrated. Third, physics education has obviously less research on student differences [17]. This is consistent with the results of this research, but it is not difficult to find that the research on physics education in China is moving closer to the research on international physics education.

After the promulgation of the 2017 version of the curriculum standard, all aspects of physics education in China have developed rapidly, with particular emphasis on the development of the core literacy of students in physics, which corresponds to the hot spots of student development in The Physics Teacher, while other fields such as student diversity, The penetration of the history of physics and the combination of information technology and education can also provide ideas and ideas for the development of physics education in China. 
Students are the protagonists of learning, and teaching must conform to the cognitive development of students. More in-depth research on the cognitive development of students' physics is a necessity and prerequisite for doing a good job in physics teaching. The diversity of students has always been a problem that people are very concerned about in teaching. The "Teaching students in accordance with their aptitude" mentioned by Confucius was first born due to the differences of students, but in physics education research in China research, we rarely meet each other. If we want to improve the national physics education level, we must conduct in-depth research on the differences of students.

Infiltrating the history of physics into physics education and teaching is also an effective supplement and important resource for physics teaching. Teachers make reasonable use of the history of physics in teaching to help students establish a correct scientific outlook, stimulate their learning interest and learning emotions, and promote students to transform from passive learning to active learning, thereby improving the effectiveness of classroom teaching and cultivating students' scientific literacy [18].

With the development of the times, science and technology are becoming more and more developed, and the conditions for the development of physics education in China are getting better and better. The application of information technology, especially multimedia technology, in physics education is extremely important. Modern information technology with multimedia, networking, and intelligence as its main characteristics is having a profound impact and transformational effect on traditional curriculum concepts, curriculum content, curriculum implementation and curriculum resources [19]. Keeping up with the pace of the times, making full use of modern information technology and physics teaching to combine to continuously improve classroom efficiency, improve the level of physics education in China, and enhance the core literacy of students is our ultimate goal.

\section{Enlightenment}

For Chinese education sector, keeping abreast of international education research fields and hotspots and paying attention to the results of international physics teaching research is an important way to improve the level of physics education, promote the development of basic physics education and the professional development of teachers, and promote teaching reform and innovation. In recent years, although Chinese physics education pays more attention to the core literacy of the subject, in general, the research field is still narrow compared with foreign countries. In addition to the research on physics knowledge and subject core literacy, research in other fields such as the development of physics cognition, student differences, the history of physics, and the combination of modern information technology and physics education are all worth exploring and exploring.

For researchers and teachers in front-line teaching, grasping the current dif- 
ferences between the current domestic and international physics education research hotspots can better start from the actual situation of physics education in China, combine first-line teaching to conduct more in-depth research and exploration, and constantly discover new problems and generate new thinking in the combination of research and teaching. For example, in the teaching process, teachers can effectively combine the history of physics with the content taught, or introduce the history of physics as a classroom throughout the classroom to make the ins and outs of knowledge clearer, stimulate students' interest in learning, consolidate knowledge, and improve teaching effect.

In 2013, the Ministry of Education initiated the revision of general high school curriculum. One of the basic principles of the revision work is to "adhere to reflect the requirements of the times", reflect advanced educational ideas and concepts, pay attention to the teaching reform in the information environment, and pay attention to the personalization and personalization of students. Diversified learning and development needs promote the transformation of talent training models and focus on the development of students' core literacy [20]. Curriculum revision work must not only integrate specific education situation in China, but also have an international perspective. The research hotspots of The Physics Teacher in the past five years drawn in this article are conducive to grasping the hotspots of international physics education, expanding international horizons, absorbing foreign excellent reform experience, and understanding educational trends in the information environment, such as learning models and student development etc. Perhaps it can provide a reference for the next revision of the curriculum standard and discover new developments in time. Continuously update and improve on the basis of inheritance, so as to establish a curriculum system with an international perspective and make it full of vitality.

\section{Conflicts of Interest}

The authors declare no conflicts of interest.

\section{References}

[1] Wang, T.J., Zhao, Z.C., Tang, Z.M., Guo, T.D. and Lin, D.L. (2020) 40 Years of Middle School Physics Teaching Research: Core Themes and Evolutionary Trends-Based on the Visual Analysis of 12173 Papers in The Physics Teacher (in Chinese) from 1980 to 2020. The Physics Teacher, 41, 7-12. (In Chinese)

[2] Cui, L., Liu, W., Yan, L., Zhang, H., Hou, Y.F., Huang, Y.N. and Zhang, H. (2008) Development of Bibliographic Information Co-Occurrence Mining System in Literature Database. Modern Library and Information Technology, No. 8, 70-75. (In Chinese)

[3] Chen, Y., Chen, C.M., Liu, Z.Y., Hu, Z.G. and Wang, X.W. (2015) Methodological Function of CiteSpace Knowledge Graph. Research in Science of Science, 33, 242-253. (In Chinese)

[4] Wei, Q.Y., Hou, G.N. and Huo, R. (2012) Statistical Analysis of Research Hotspots in Domestic Information Science Master's Degree Thesis in the Past 10 Years. Library and Information Service, 56, 35-39+81. (In Chinese) 
[5] James, W., Cooney, J.H., Chini, J.J., Vasquez, E. and Schreffler, J. (2021) Using Universal Design for Learning to Support Students with Disabilities in a SCALE-UP Physics Course. The Physics Teacher, 59, 320-324. https://doi.org/10.1119/10.0004878

[6] Luisa, L., Markus, P., Sarah, M., Kristin, A., Roland, B., Hamraz, J., Orkhan, A., Agnes, G. and Paul, L. (2020) Real-Time Visualization of Electrical Circuit Schematics: An Augmented Reality Experiment Setup to Foster Representational Knowledge in Introductory Physics Education. The Physics Teacher, 58, 518. https://doi.org/10.1119/10.0002078

[7] Louis, L. and Melissa, H. (2021) Designing Laboratories for Online Instruction Using the iOLab Device. The Physics Teacher, 59, 351-355. https://doi.org/10.1119/10.0004886

[8] Rubin, S. (2019) A Variable-Mass Snowball Rolling Down a Snowy Slope. The Physics Teacher, 57, 150-151. https://doi.org/10.1119/1.5092471

[9] Armand Le Noxaïc. A. (2014) Spectacular Experiment Exhibiting Atmospheric Pressure. The Physics Teacher, 52, 223-225. https://doi.org/10.1119/1.4868935

[10] Dew, M., Ford, L., Nodurft, D.T., Erukhimova, T. and Perry, J. (2021) Student Responses to Changes in Introductory Physics Learning Due to the COVID-19 Pandemic. The Physics Teacher, 59, 162-165. https://doi.org/10.1119/5.0027816

[11] Trout, K.P., Adkins, M., Bekker, J., Harlacher, A., Ramirez, F., Swingler, A. and Wagner, C. (2021) Using iPads for Video Analysis Physics Labs in Times of Social Isolation. The Physics Teacher, 59, 370. https://doi.org/10.1119/10.0004893

[12] Frodyma, M. and Le, M.P. (2018) Using the Cycloid as an Introduction to Transformations of E and B Fields. The Physics Teacher, 56, 304-306. https://doi.org/10.1119/1.5033875

[13] Yang, E. (2016) Use of a Mobile Application to Help Students Develop Skills Needed in Solving Force Equilibrium Problems. The Physics Teacher, 54, 108. https://doi.org/10.1119/1.4940177

[14] Erlichson, H. (2008) The Role of History in Liberal Arts Physics. The Physics Teacher, 46, 452. https://doi.org/10.1119/1.2999056

[15] Mungan, C.E. (2021) A Race between Rolling and Sliding Up and down an Incline. The Physics Teacher, 59, 247. https://doi.org/10.1119/10.0004147

[16] Teng, B., Teng, P. and Hennekens, C.H. (2018) A Simple Way to Teach Single Slit Diffraction Based on Edge Diffraction. The Physics Teacher, 56, 380-383. https://doi.org/10.1119/1.5051152

[17] Zhai, X.M. and Guo, Y.Y. (2015) Analysis and Enlightenment of International Physics Education Research Hot Spots in the Past Ten Years. Global Education Outlook, 44, 108-117+124. (In Chinese)

[18] Liu, X.S. (2021) Giving Play to the Educating Role of the History of Physics in Physics Teaching. Basic Education Curriculum, No. Z1, 84-87. (In Chinese)

[19] Zhang, S.P. (2013) A Brief Discussion on the Integration of Modern Information Technology and Physics. Examination Weekly, No. 44, 135. (In Chinese)

[20] Organized and Compiled by the Ministry of Education's Basic Education Curriculum and Textbook Expert Working Committee; Ordinary High School Physics Curriculum Standard Revision Group (2020) Interpretation of Ordinary High School Physics Curriculum Standards (2017 Edition and 2020 Revision). Higher Education Press, Beijing. 